\title{
Mental Health of Physical Therapy Students in Clinical Practice during the COVID-19 Pandemic: A Cross-sectional Survey in Gwangju and Jeollanam-do, South Korea
}

\author{
Se Ju Park, Seong Geun Yeo, Byeong Geun Kim \\ Department of Physical Therapy, Nambu University, Gwangju, Republic of Korea
}

Purpose: The purpose of this study was to investigate the mental health of physical therapy students in clinical practice during the COVID-19 pandemic.

Methods: A cross-sectional survey was conducted during the pandemic and was completed by 100 physical therapy students in two universities in Gwangju and Jeollanam-do, South Korea. The Generalized Anxiety Disorder-7 (GAD-7) scale and the Patient Health Questionnaire-9 (PHO-9) were used to evaluate their anxiety and depression status. A Chi-square test was conducted to evaluate the association of participant characteristics with the risk of having anxiety and depression. Logistic regression models were used to identify the general characteristic factors related to anxiety or depression.

Results: Anxiety was found in 28 (28\%) of the participants, and depression in 24 (24\%). The risk of anxiety and depression in male physical therapy students was 0.189 and 0.211 times lower, respectively, than those female students $(p<0.05)$. The risk of anxiety and depression in physical therapy students with a history of disease was 11.721 and 7.056 times higher, respectively, than those with a history of disease $(p<0.05)$. The risk of anxiety in physical therapy students in clinical practice was 11.721 times higher than that in students who were not in clinical practice $(p<0.05)$.

Conclusion: The COVID-19 pandemic has led to a high risk of anxiety and depression among many physical therapy students. More attention and improvements are needed so that physical therapy students can study in a safe environment.

Keywords: COVID-19, Mental health, Anxiety, Depression, Physical therapy students

\section{INTRODUCTION}

The spread of COVID-19 around the world has resulted in millions of people being infected or dying. The first case in South Korea was reported on January 20, 2020, and infections and deaths continue to occur. The Korean government is implementing national measures to prevent and treat COVID-19.1,2 As a result of the pandemic, many people have developed anxiety their mental health affected. ${ }^{3,4}$

The mental health of medical professionals working in hospitals has been affected by the COVID-19 pandemic., ${ }^{5,6}$ Medical students will experience clinical practice in the medical field? Therefore, in recent years, it is not only medical professionals who are taking part in mental health surveys but also students in the medical field. Previous studies have reported

Received May 14, 2021 Revised Jun 18, 2021

Accepted Jun 28, 2021

Corresponding author Byeong Geun Kim

E-mail qudrms_92@naver.com that medical students have a fear of COVID-19. ${ }^{8}$ Another study found that among students majoring in dentistry, the COVID-19 pandemic had a psychological effect on clinical practice. ${ }^{9}$ However, there is still a lack of literature on the mental health of students majoring in physical therapy during clinical practice.

In hospitals, patients can be vulnerable to viral infection. ${ }^{10}$ The spread of infectious diseases within hospitals was confirmed to originate from medical staff who were engaged in activities outside the hospital rather than from patients. ${ }^{11}$ As COVID-19 spread in Gwangju and Jeollanam-do in the first half of summer of 2020, clinical practice among students who are in easy contact with the outside in hospitals and universities was temporarily suspended and a transition to full-fledged non-face-to-face clinical practice occurred. As the spread of COVID-19 decreased, clinical

Copylight (C2021 The Korean Society of Physical Therapy

This is an Open Access article distribute under the terms of the Creative Commons Attribution Non-commercial License (https:// creativecommons.org/license/by-nc/4.o.) which permits unrestricted non-commercial use, distribution, and reproduction in any medium, provided the original work is properly cited. 
practice resumed in hospitals and universities in the second half or winter of 2020. Therefore, the purpose of this study was to investigate the mental health of physical therapy students in clinical practice during the COVID-19 pandemic.

\section{METHODS}

\section{Study design and Subjects}

This cross-sectional study was conducted for one week each on November 23,2020 , and February 17, 2021. Both surveys were conducted one month after the beginning of clinical practice. A convenience sampling strategy was used. The participants of this study were 100 physical therapy students from two universities in Gwangju and Jeollanam-do, South Korea. Students from the Department of Physical Therapy N and J university were included in this study. Physical therapy students who had been diagnosed with mental health-related diseases before the COVID-19 pandemic and those who were currently taking drugs for mental illness-related conditions were excluded from the study.

\section{Survey}

The survey was comprised of three parts: participants' characteristics (age range, gender, family members living together, history of disease, self-isolation experience, COVID-19 test experience, and clinical practice type), anxiety, and depression. Anxiety and depression were measured using the Generalized Anxiety Disorder Scale (GAD-7) ${ }^{12}$ and the Patient Health Questionnaire-9 (PHQ-9), ${ }^{13}$ respectively, according to the guidelines of the National Center for Mental Health. The GAD-7 is a seven-item scale with total scores ranging from 0 to $21{ }^{12}$ On the other hand, the PHQ-9 is a nine-item scale with total scores ranging from 0 to $27 .{ }^{13}$ According to the guidelines of the National Center for Mental Health, a total score of 5 or higher for each scale was considered as anxiety and depression.

\section{Procedure}

A questionnaire was completed through an online Google Form. Ethics approval was obtained from the Institutional Review Board of the N University (IRB1041478-2020-HR-039). All respondents provided informed consent.

\section{Statistical analysis}

All statistical analyses were conducted using the Statistical Package for the Social Sciences (SPSS for Windows, version 21.0; IBM, Chicago, IL). Data were presented as frequencies and percentages. A Chi-square test was conducted to evaluate the association of participants' characteristics with the risk of having anxiety and depression. In the case of a significant association was found, binary logistic regression analysis was conducted for clearer results regarding risk factors. All tests were two-tailed, with a significance level of $\mathrm{p}<0.05$.

\section{RESULTS}

This study surveyed 100 physical therapy students from two universities. Anxiety was found in 28 (28\%) of the participants, and depression in 24 (24\%)(Tables 1, 2). There was a significant relationship between anxiety, depression, and the participants' characteristics (gender, disease history, practice type) $(\mathrm{p}<0.05)($ Tables 1,2$)$. Related general characteristic variables and their effects on having anxiety and depression were further identified. The risk of having anxiety and depression in male physical therapy students was 0.189 and 0.211 times lower, respectively, than those in female students $(\mathrm{p}<0.05)($ Table 3$)$. The risk of having anxiety and depression in physical therapy students with a history of disease was 11.721 and 7.056 times higher, respectively, than that in students with no disease history $(\mathrm{p}<0.05)$ (Table 3). The risk of having anxiety in physical therapy students in clinical practice was 11.721 times higher than that in students who weren't in clinical practice $(\mathrm{p}<0.05)$ (Table 3$)$.

\section{DISCUSSION}

This is the first study to investigate mental health among students majoring in physical therapy in clinical practice during the COVID-19 pandemic. The study found that $28 \%$ of physical therapy students had anxiety and $24 \%$ had depression during clinical practice. In a mental health survey conducted on university students in China in 2020, the prevalence of anxiety and depression were $26.6 \%$ and $21.16 \%$, respectively, similar to the proportion of students majoring in physical therapy who participated in this study. ${ }^{14}$ These results are thought to be the result of many people feeling anxious when a pandemic of an infectious disease such as COVID-19 occurs. ${ }^{15}$ Therefore, it is necessary to provide correct information about COVID-19 as well as coping measures and psychological counseling programs within the universities.

In this study, male students majoring in physical therapy during clinical practice had a lower risk of anxiety and depression compared to that in female students. The results of this study were consistent with those in liter- 
Table 1. Association of participants characteristics of physical therapy students with presence of anxiety

\begin{tabular}{|c|c|c|c|c|}
\hline Variable & Total & Anxiety & Non-Anxiety & $\mathrm{p}$ \\
\hline Total, n (\%) & $100(100)$ & $28(28)$ & $72(72)$ & \\
\hline \multicolumn{5}{|l|}{ Age range } \\
\hline $20 \mathrm{~s}$ & 93 & 26 & 67 & 0.374 \\
\hline $30 \mathrm{~s}$ & 5 & 1 & 4 & \\
\hline $40 \mathrm{~s}$ & 1 & 0 & 1 & \\
\hline $50 \mathrm{~s}$ & 1 & 1 & 0 & \\
\hline \multicolumn{5}{|l|}{ Gender } \\
\hline Male & 46 & 6 & 40 & $0.002^{*}$ \\
\hline Female & 54 & 22 & 32 & \\
\hline \multicolumn{5}{|l|}{ Family members living together } \\
\hline Alone & 39 & 12 & 27 & 0.163 \\
\hline$\leq 7$-yr-old in family & 3 & 2 & 1 & \\
\hline 8-64-yr-old in family & 54 & 13 & 41 & \\
\hline$\geq 65$-yr-old in family & 3 & 0 & 3 & \\
\hline$\leq 7$ and $\geq 65$-yr-old in family & 1 & 1 & 0 & \\
\hline \multicolumn{5}{|l|}{ History of disease } \\
\hline Yes & 28 & 6 & 22 & $0.002^{*}$ \\
\hline No & 72 & 2 & 70 & \\
\hline \multicolumn{5}{|l|}{ Self-isolation experience } \\
\hline Yes & 4 & 2 & 2 & 0.317 \\
\hline No & 96 & 26 & 70 & \\
\hline \multicolumn{5}{|l|}{ COVID-19 test experience } \\
\hline Yes & 18 & 5 & 13 & 0.981 \\
\hline No & 82 & 23 & 59 & \\
\hline \multicolumn{5}{|l|}{ Clinical practice type } \\
\hline Face-to-face & 56 & 23 & 33 & $0.001 *$ \\
\hline Non-face-to-face & 44 & 5 & 39 & \\
\hline
\end{tabular}

${ }^{*} p<0.05$.

ature where female individuals were more anxious and depressed than male individuals during the COVID-19 pandemic. $^{16,17}$ In this study, many factors affected male and female students' mental health, however, it is thought that this might be because female individuals often have internalized symptoms and male individuals have externalized symptoms. In previous studies, female individuals' mental health problems were different from female individuals' physical factors, and internalization symptoms were reported..$^{18}$ As an example of internalization and externalization symptoms, it was reported that female individuals are sensitive to interpersonal relationships, while male individuals are sensitive to career and goal-oriented factors. ${ }^{19}$

In this study, physical therapy students with a history of disease during clinical practice had a higher risk of anxiety and depression than that in students without disease history. Previous studies have reported on the association between various diseases and COVID-19. ${ }^{20-22}$ Many people are already aware of the same content as previous studies, so people with a history of disease are thought to be affected by mental health problems because they tend to be more careful not to get infected with COVID-19. Previous studies also reported that people with a history of disease were mental likely to experience mental health problems. ${ }^{23,24}$

In this study, students majoring in physical therapy who attended faceto-face clinical practice during this period had a higher risk of anxiety than that in students in non-face-to-face clinical practice. In face-to-face practice, there is a risk of infection from within the hospital and spreading the infection outside, and there is also a risk of being infected outside the hospital and spreading it inside the hospital. In addition, through this study, it was found that it has an effect on the mental health of students. Therefore, it is necessary to develop a systematic non-face-to-face clinical practice program that can ensure the safety of physical therapy students similar to that of medical students in other fields.

There are several limitations to this study. First, only two universities participated, the number of participants was small. Second, this study did 
Table 2. Association of participants characteristics of physical therapy students with presence of depression

\begin{tabular}{|c|c|c|c|c|}
\hline Variable & Total & Depression & Non-Depression & $\mathrm{p}$ \\
\hline Total, n (\%) & $100(100)$ & $24(24)$ & $76(76)$ & \\
\hline \multicolumn{5}{|l|}{ Age range } \\
\hline $20 \mathrm{~s}$ & 93 & 22 & 71 & 0.317 \\
\hline $30 \mathrm{~s}$ & 5 & 1 & 4 & \\
\hline $40 \mathrm{~s}$ & 1 & 0 & 1 & \\
\hline $50 \mathrm{~s}$ & 1 & 1 & 0 & \\
\hline \multicolumn{5}{|l|}{ Gender } \\
\hline Male & 46 & 5 & 41 & $0.005^{*}$ \\
\hline Female & 54 & 19 & 35 & \\
\hline \multicolumn{5}{|l|}{ Family member } \\
\hline Alone & 39 & 9 & 30 & 0.370 \\
\hline$\leq 7$-yr-old in family & 3 & 1 & 2 & \\
\hline 8-64-yr-old in family & 54 & 13 & 41 & \\
\hline$\geq 65$-yr-old in family & 3 & 0 & 3 & \\
\hline$\leq 7$ and $\geq 65$-yr-old in family & 1 & 1 & 0 & \\
\hline \multicolumn{5}{|l|}{ History of disease } \\
\hline Yes & 8 & 5 & 3 & $0.008^{*}$ \\
\hline No & 92 & 19 & 73 & \\
\hline \multicolumn{5}{|l|}{ Self-isolation experience } \\
\hline Yes & 4 & 2 & 2 & 0.214 \\
\hline No & 96 & 22 & 74 & \\
\hline \multicolumn{5}{|l|}{ COVID-19 test experience } \\
\hline Yes & 18 & 5 & 13 & 0.679 \\
\hline No & 82 & 19 & 63 & \\
\hline \multicolumn{5}{|l|}{ Clinical practice type } \\
\hline Face-to-face & 56 & 19 & 37 & $0.009^{*}$ \\
\hline Non-face-to-face & 44 & 5 & 39 & \\
\hline
\end{tabular}

${ }^{*} p<0.05$.

Table 3. Binary logistic regression analysis for the risk factor of participants characteristics associated with anxiety and depression

\begin{tabular}{|c|c|c|c|c|c|c|}
\hline \multirow{2}{*}{ Comparison } & \multicolumn{3}{|c|}{ Anxiety } & \multicolumn{3}{|c|}{ Depression } \\
\hline & OR & $95 \% \mathrm{Cl}$ & $\mathrm{p}$ & OR & $95 \% \mathrm{Cl}$ & $\mathrm{p}$ \\
\hline Male vs. Female & 0.189 & $0.057-0.623$ & $0.006^{*}$ & 0.211 & $0.063-0.704$ & $0.011^{*}$ \\
\hline History of disease Yes vs No & 11.721 & $1.651-83.194$ & $0.014^{*}$ & 7.056 & $1.223-40.719$ & $0.029^{*}$ \\
\hline Face-to-face vs Non-face-to-face & 3.827 & $1.232-11.885$ & $0.020^{*}$ & 2.735 & $0.872-8.580$ & 0.085 \\
\hline
\end{tabular}

OR: odds ratio, Cl: confidence interval.

${ }^{*} p<0.05$.

not have a control group or longitudinal follow-up. Third, the student's academic stress and environment were not taken into consideration. Therefore, further investigation is needed to compensate for these limitations.

The COVID-19 pandemic has a high risk of causing anxiety and depression among many physical therapy students. Female students, students with a history of disease, and students who are in face-to-face clinical practice should pay attention to their mental health. The mental health of students majoring in physical therapy should be continuously moni- tored. Greater attention and improvements are needed to enable a safe environment for physical therapy students in clinical practice.

\section{REFERENCES}

1. Shim E, Tariq A, Choi W et al. Transmission potential and severity of COVID-19 in South Korea. Int J Infect Dis. 2020;93:339-44.

2. Cho SI. Academic community's efforts to guide the fight against coronavirus disease 2019 (COVID-19) epidemic in Korea. J Prev Med Public 
Health. 2020;53(2):65-6.

3. Ren SY, Gao RD, Chen YL. Fear can be more harmful than the severe acute respiratory syndrome coronavirus 2 in controlling the corona virus disease 2019 epidemic. World J Clin Cases. 2020;8(4):652-7.

4. Bo HX, Li W, Yang Y et al. Posttraumatic stress symptoms and attitude toward crisis mental health services among clinically stable patients with COVID-19 in China. Psychol Med. 2021;51(6):1052-3.

5. Demartini K, Konzen VDM, Siqueira MDO et al. Care for frontline health care workers in times of COVID-19. Rev Soc Bras Med Trop. 2020; 53:e20200358.

6. Sahin MK, Aker S, Sahin G et al. Prevalence of depression, anxiety, distress and insomnia and related factors in healthcare workers during COVID-19 pandemic in Turkey. J Community Health. 2020;45(6):1168-77.

7. Choi YH. Hospital infection control practice in the COVID-19 era: an experience of university affiliated hospital. Korean J Med. 2020;95(5): 308-14.

8. Nguyen HT, Do BN, Pham KM et al. Fear of COVID-19 scale-associations of its scores with health literacy and health-related behaviors among medical students. Int J Environ Res Public Health. 2020;17 (11):4164.

9. Osman A, Tuba TY. Evaluation of knowledge, attitudes, and clinical education of dental students about COVID-19 pandemic. PeerJ. 2020;8: e9575.

10. Maltezou HC, Dedoukou X, Tsonou P et al. Hospital factors associated with SARS-CoV-2 infection among healthcare personnel in Greece. J Hosp Infect. 2021;109:40-3.

11. Rosario B, Francesco V. Covid-19 and infection in health-care workers: an emerging problem. Med Leg J. 2020;88(2):65-6.

12. Spitzer RL, Kroenke K, Williams JB et al. A brief measure for assessing generalized anxiety disorder: the GAD-7. Arch Intern Med. 2006;166 (10):1092-7.

13. Kroenke K, Spitzer RL, Williams JB. The PHQ-9: validity of a brief depression severity measure. J Gen Intern Med. 2001;16(9):606-13.

14. Jinghui $C$, Yuxin Y, Dong W. Mental health status and its influencing fac- tors among college students during the epidemic of COVID-19. Nan Fang Yi Ke Da Xue Xue Bao. 2020;40(2):171-6.

15. Ren SY, Gao RD, Chen YL. Fear can be more harmful than the severe acute respiratory syndrome coronavirus 2 in controlling the corona virus disease 2019 epidemic. World J Clin Cases. 2020;8(4):652-7.

16. Sofia P, Vasiliki N, Timoleon G et al. Prevalence of depression, anxiety, and insomnia among healthcare workers during the COVID-19 pandemic: a systematic review and meta-analysis. Brain Behav Immun. 2020;88:901-7.

17. Nina V, Michael EB. COVID-19 pandemic and mental health consequences: systematic review of the current evidence. Brain Behav Immun. 2020;89:531-42.

18. Paul RA. Why is depression more prevalent in women? J Psychiatry Neurosci. 2015;40(4):219-21.

19. Kenneth SK, Charles OG. Sex differences in the pathways to major depression: a study of opposite-sex twin pairs. Am J Psychiatry. 2014;171 (4):426-35.

20. Gao C, Cai Y, Zhang K et al. Association of hypertension and antihypertensive treatment with COVID-19 mortality: a retrospective observational study. Eur Heart J. 2020;41(22):2058-66.

21. Fabio P, Graziamaria C, Grazia M et al. COVID-19 and the elderly: insights into pathogenesis and clinical decision-making. Aging Clin Exp Res. 2020;32(8):1599-608.

22. Yingzhen D, Lei T, Pingjun Z et al. Clinical features of 85 fatal cases of COVID-19 from Wuhan. a retrospective observational study. Am J Respir Crit Care Med. 2020;201(11):1372-9.

23. Zhou Z, Shabei X, Hui W et al. COVID-19 in Wuhan: sociodemographic characteristics and hospital support measures associated with the immediate psychological impact on healthcare workers. EClinicalMedicine. 2020;24:100443.

24. Zahra A, Abdallah YN, Fatemah MA et al. Mental health status of healthcare professionals and students of health sciences faculties in kuwait during the COVID-19 pandemic. Int J Environ Res Public Health. 2021;18(4):2203. 